[5] А. И. Павлов, “Повышение адекватности имитационных моделей нелинейных диссипативных объектов,” Автоматизация технологических и бизнес-процессов, ном. 17, сс. 4-7, 2014;

[6] А. И. Павлов, “Виртуальный стенд для определения оптимального по быстродействию исполнительного устройства," Автоматизация технологических и бизнес-процессов, вып. 6, ном. 4, сс. 130-137, 2014;

[7] А. И. Павлов, “Динамическая коррекция коэффициента передачи пропорционально-интегрального регулятора,” Автоматизация технологических и бизнес-процессов, вып. 7, ном. 1, сс. 31-34, 2015;

[8] А. И. Павлов, “Система автоматического регулирования температуры нестационарного объекта,” Автоматизация технологических и бизнес-процессов, вып. 7, ном. 2, сс. 31-34, 2015;

[9] А. И. Павлов, “Каскадная система автоматического регулирования с нестационарным объектом," Автоматизация технологических и бизнес-процессов, вып. 8, ном. 3, сс. 4-9, 2015;

[10] А. И. Павлов, “Простой ПИ-подобный регулятор с континуальной логикой для нестационарных объектов,” Автоматизация технологических и бизнес-процессов, вып. 9, ном. 1, сс. 65-71, 2016.

\title{
ESTIMATION OF THE WIDTH OF THE STATIONARY DETONATION WAVE IN THE MODEL OF ZEL'DOVICH- NEUMANN-DÖRING
}

\author{
A. S. Tityapkin ${ }^{1}$, V. E. Volkov ${ }^{2}$ \\ ${ }^{1}$ Ukrainian Scientific Center of Ecology of the Sea, Odessa \\ ${ }^{2}$ Odessa National Academy of food technologies, Odessa \\ Copyright (C) 2014 by author and the journal "Automation technological and business - processes". \\ This work is licensed under the Creative Commons Attribution International License (CC BY). \\ http://creativecommons.org/licenses/by/4.0/
}

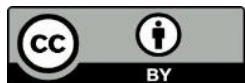

ONAFT

Open Access

Abstract: The models of Chapman-Jouget and Zel'dovich-Neumann-Döring are considered to estimate the width of a detonation wave in gas mixtures. Improved software package was developed earlier. The calculations of stationary detonation wave width are in good agreement with the experimental data. Estimation of the stationary detonation wave width is important for the detonation control.

Key words: The detonation wave, the width of the stationary detonation wave, ZND model, software complex, control.

From the viewpoint of explosion protection the most important problems are the detonation initiation, the structure of detonation waves, the detonation limits (on concentration and initial pressure), and the limiting detonation regime (spin and a gallop). All of these problems are connected with the problem of stability of one-dimensional stationary detonation wave. A detailed analysis of the detonation wave instability allows to calculate the structure of multifront (cellular) detonation, estimating the cell size by the wave length of perturbations with maximum velocity for amplitude increase. The inversely proportional dependence between the detonation cell size and the initial combustible mixture pressure allows to control the detonation process, which is important for solving practical problems of explosion. For these cases a problem of estimation for a detonation wave width, including a chemical reaction zone and / or the induction zone, is important, especially if there are no experimental data. Solving of this problem is the purpose of this study.

V.A. Michelson [1] was the first who gave physical explanation for observations of detonations in gas mixtures. Chapman and Jouget [2, 3] developed idea about detonation wave as a shock wave with the small time of chemical transformation directly in the front. Reaction zone was considered simply as a surface of discontinuity. Their hypothesis that the velocity of detonation products is equal to the local velocity of sound closed the set of equations consisting of conservation laws and the 
equation of state. Coincidence of calculations and experimental data was the best confirmation of the validity of this classical hydrodynamic theory. However this theory doesn't explain existence of limits for detonation propagation, because the width of reaction zone simply equals zero.

Zel'dovich (USSR, 1940) [4], von Neumann (USA, 1942) [5] and Döring (Germany, 1943) [6] analyzed and substantiated mechanism of selection for Jouget states. One-dimensional model of the detonation front structure proposed by them was named model of Zel'dovich-Neumann-Döring (ZND). The appearance of this model, complemented hydrodynamic theory of Chapman-Jouget and completed formation of the classical theory of detonation.

According to the classical ZND-model, transfer of detonation is caused by the shock propagation on explosive, that could initiate an intense chemical reaction. Energy-release of chemical reaction maintains the constancy of wave's parameters and stationary character of detonation process as a whole. There are gradually expanding detonation products behind the chemical reaction zone. Thus, the propagation of the detonation wave consists of a shock wave, the chemical reaction zone and final detonation products. As it is shown in Fig. 1 the initial explosive is separated from the chemical reaction zone of the shock wave $\mathrm{B}-\mathrm{B}$, and the surface $\mathrm{H}-\mathrm{H}$ separates the chemical reaction zone and the detonation products for stationary detonation. So after compression by shock wave the initial explosive gets into the point B (the Neumann peak), and then it goes into the point $\mathrm{H}$ (the Chapman-Jouget point) during the chemical reaction.

For a description of the stationary detonation process it is enough to compare the state of the initial explosive, the shockcompressed state and the reaction products:

$$
\left\{\begin{array}{l}
w_{0} \rho_{0}=w_{1} \rho_{1}=w_{2} \rho_{2} \\
p_{0}+\rho_{0} w_{0}^{2}=p_{1}+\rho_{1} w_{1}^{2}=p_{2}+\rho_{2} w_{2}^{2} \\
\frac{\gamma_{0}}{\gamma_{0}-1} \frac{p_{0}}{\rho_{0}}+\frac{w_{0}^{2}}{2}+Q=\frac{\gamma_{0}}{\gamma_{0}-1} \frac{p_{1}}{\rho_{1}}+\frac{w_{1}^{2}}{2}+Q=\frac{\gamma_{2}}{\gamma_{2}-1} \frac{p_{2}}{\rho_{2}}+\frac{w_{2}^{2}}{2}, \\
w_{2}^{2}=\frac{\gamma_{2} p_{2}}{\rho_{2}}
\end{array}\right.
$$

where $w_{0}$ - detonation velocity that equals to the velocity of the chemical reaction zone;

$w_{2}$ - detonation velocity relative to the reaction products;

$\rho_{0}, p_{0}, \gamma_{0}-$ state parameters (pressure, density, and the ratio of specific heats respectively) of initial explosive in front of the chemical reaction zone;

$\rho_{1}, p_{1}, \gamma_{1}=\gamma_{0}$ - state parameters of the shock-compressed state for the initial explosive;

$\rho_{2}, p_{2}, \gamma_{2}-$ state parameters of products behind a chemical reaction zone;

$Q-$ specific heat of explosive conversion.

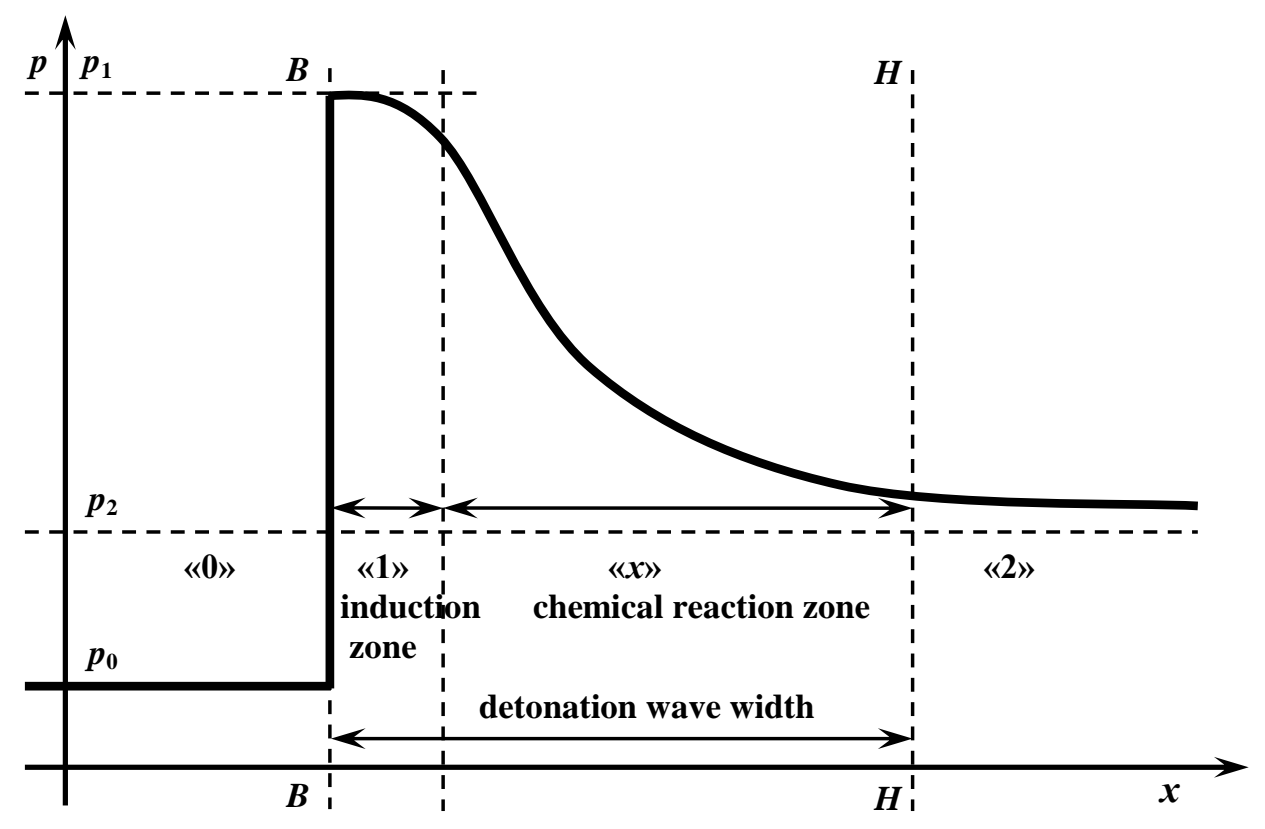

Fig. 1 - Pressure profile of detonation in ZND-theory 
For the intermediate states in the chemical reaction zone there is dependence between the internal energy and chemical composition. Thus, the processes in the stationary detonation wave are considered with the kinetics of chemical reactions that produce heat. For simplicity, it is assumed that the chemical kinetics equations can be written with a single variable. Concentration by weight of a substance $\beta$ is selected as such a variable. The dependence of all values on time is determined by the equation of chemical kinetics. Consequently, ZND detonation model can be written as a set of equations for conservation laws of mass, momentum and energy, applicable to any control surface inside the detonation wave, and equations of chemical kinetics:

$$
\left\{\begin{array}{l}
w_{0} \rho_{0}=w(x) \rho(x) \\
p_{0}+\rho_{0} w_{0}^{2}=p(x)+\rho(x) w^{2}(x) \\
\frac{\gamma_{0}}{\gamma_{0}-1} \frac{p_{0}}{\rho_{0}}+\frac{w_{0}^{2}}{2}+Q=\frac{\gamma}{\gamma-1} \frac{p(x)}{\rho(x)}+\frac{w^{2}(x)}{2}+\beta(x) Q \\
\frac{d \beta(x)}{d t}=-\beta(x)^{m} f(p(x), \rho(x)) \\
\gamma=\gamma_{0} \beta(x)+\gamma_{2}(1-\beta(x))
\end{array}\right.
$$

with such conditions:

$$
\left\{\begin{array} { l } 
{ p ( 0 ) = p _ { 1 } } \\
{ \rho ( 0 ) = \rho _ { 1 } } \\
{ w ( 0 ) = w _ { 1 } } \\
{ \beta ( 0 ) = 1 }
\end{array} \text { and } \left\{\begin{array}{l}
p(L)=p_{2} \\
\rho(L)=\rho_{2} \\
w(L)=w_{2} \\
\beta(L)=0
\end{array}\right.\right.
$$

where the exponential quantity $m$ is associated with the so-called order of reaction.

For example, for bimolecular reactions $m=2$, the function $f(p, \rho)$ is proportional to factor $p^{m-1} \exp \left(-\frac{E \rho}{\mu p}\right)$, where $E$ is the activation energy, $\mu$ is the average molecular weight.

The resulting set (2) with conditions (3) is solved numerically. And the state behind the detonation wave front at $x=L$ and the parameters of the shock-compressed state at $x=0$ (parameters in Neumann peak and Chapman-Jouget point) are found at first.

From the equations (2) it follows that $p(x), \rho(x)$ and $w(x)$ are:

$$
\begin{aligned}
& p_{x}=\frac{a+1}{\gamma+1}+\sqrt{\left(\frac{a+1}{\gamma+1}\right)^{2}+\frac{\gamma-1}{\gamma+1}\left(1-\frac{2 a}{\gamma_{0}-1}+2 a \frac{\rho_{0} Q}{p_{0}}(\beta(x)-1)\right)} \\
& \rho_{x}=\frac{a}{1+a-p_{x}} \\
& w_{x}=1+\frac{1-p_{x}}{a}
\end{aligned}
$$

where $p_{x}=\frac{p(x)}{p_{0}}, \rho_{x}=\frac{\rho(x)}{\rho_{0}}, w_{x}=\frac{w(x)}{w_{0}}, a=\frac{\rho_{0} w_{0}^{2}}{p_{0}}$.

Substituting $p(x)$ and $\rho(x)$ into the function $f(p, \rho)$ leads to equation of chemical kinetics for only one variable:

$$
\frac{d \beta}{d t}=-\varphi(\beta),
$$

where $\varphi(\beta)$ is a composite function, which is defined for each gas reaction.

The total derivative of value $\beta$ is:

$$
\frac{d \beta}{d t}=\frac{\partial \beta}{\partial t}+\frac{\partial \beta}{\partial x} \frac{d x}{d t}=-w(x) \frac{\partial \beta}{\partial x}
$$


It results from this that

$$
x=\int_{\beta}^{1} \frac{w(x)}{\varphi(\beta)} d \beta
$$

The equation of chemical kinetics in general can be represented as follows

$$
\frac{d \beta}{d t}=-L \beta^{m}(x) p^{n}(x) \rho^{l}(x) \exp \left(-\frac{E}{\mu} \frac{\rho(x)}{p(x)}\right),
$$

then:

$$
x=\int_{\beta}^{1} \frac{w(x)}{L \beta^{m}(x) p^{n}(x) \rho^{l}(x)} \exp \left(\frac{E}{\mu} \frac{\rho(x)}{p(x)}\right) d \beta,
$$

where $m, n, l$ are some constants.

Distribution of $p(x), \rho(x)$ and $w(x)$ can be obtained by numerical integration of the equations of gas dynamics and the chemical kinetics $(2,8)$. First of all the profile of pressure distribution is interesting. Calculations for gas systems on the basis of Arrhenius kinetics in its different modifications were produced in [7].

To estimate the width of a detonation wave in ZND-model the following was proposed by Zel'dovich [8]. If the function $\frac{1}{\varphi(\beta)}$ is represented by its dependence on $1-\beta$, we get a curve similar to that shown in Fig. 2 . Near the front, where $1-\beta<<1$ there is a very rapid decrease of function because of the exponential factor in the Arrhenius kinetics, and near $\beta=0$ the function increases up to infinity. But in fact, this last part is not realized in detonation regime, since the losses do not allow to finish the reaction. The width of the detonation wave is naturally defined by the values $\beta=\beta_{0}$ underlying to the right of the minimum for the curve $\frac{1}{\varphi(\beta)}$, since in fact the reaction comes only up to these values.

Thus, the width of a detonation wave can be estimated. Note that earlier this approach was proposed to use in [9], and also it was noted that most of the difference methods for calculating of detonation waves do not describe their structures, in particular, they do not estimate the width of detonation zone.

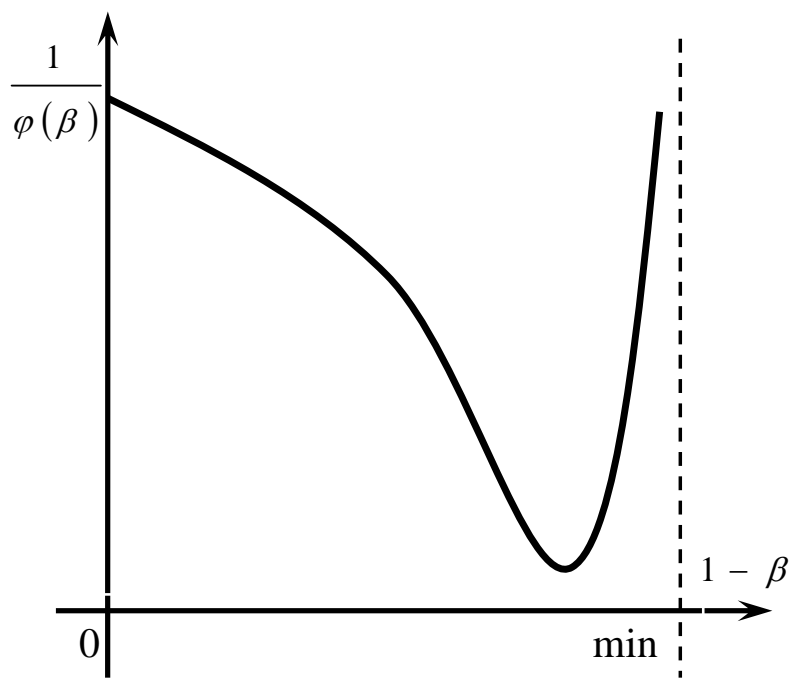

Fig. 2 - The dependence $\frac{1}{\varphi(\beta)}$ of $1-\beta$

The calculated pressure profile for stoichiometric hydrogen-oxygen mixture at $p_{0}=530 \mathrm{~mm} \mathrm{Hg}$ is shown below in Fig. 3 . The resulting value of the width of the stationary detonation front $8,63 \mathrm{~mm}$ is in good agreement with the value of $8,32 \mathrm{~mm}$ from [10]. 


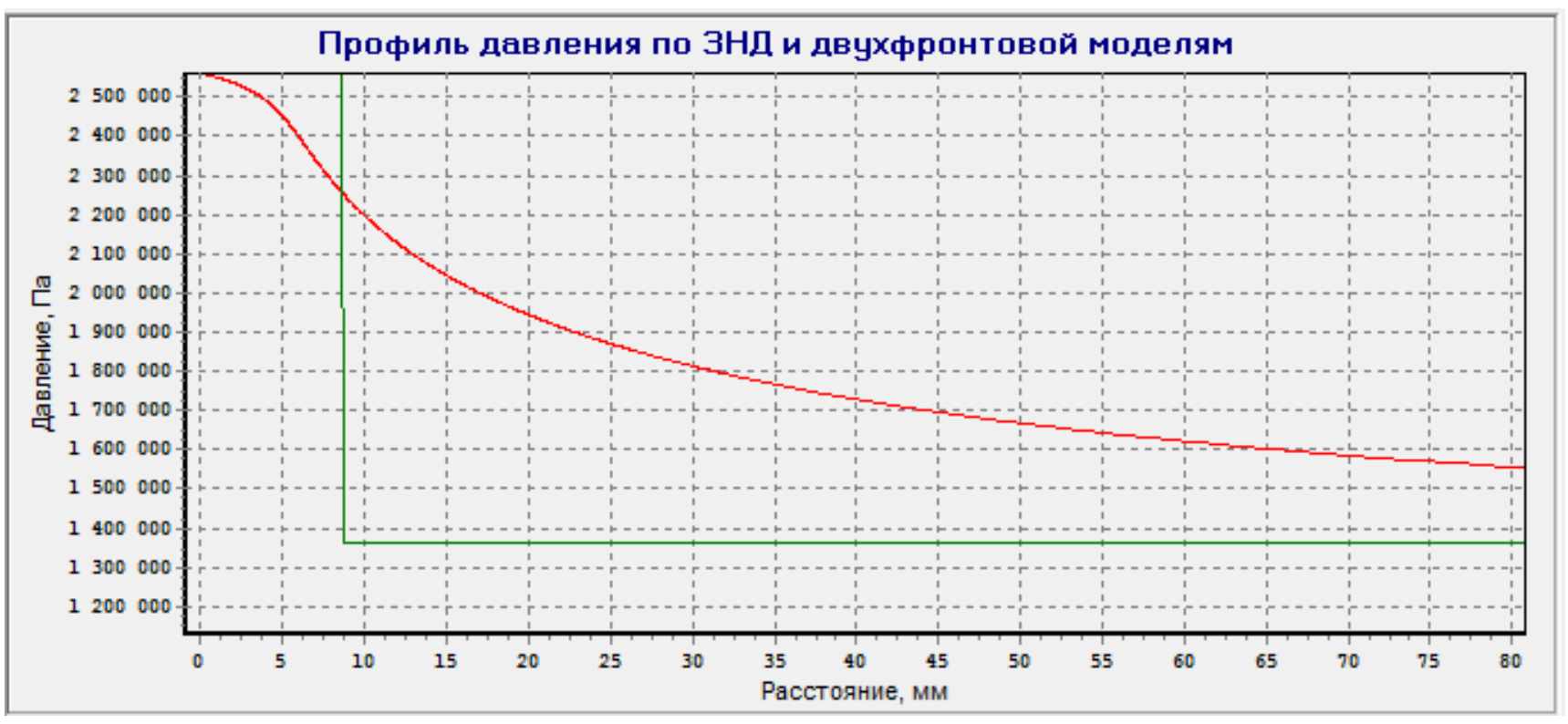

Fig. 3 - Pressure profile for stoichiometric hydrogen-oxygen mixture

For a number of other gas mixtures the good agreement with experiment was also obtained.

Correct estimation of the detonation zone width makes it possible to solve the problem of the detonation wave stability. This solution is used for control of detonation regimes.

\section{References}

[1] V. A. Michelson, "On the normal ignition velocity of explosive gaseous mixtures," Scientific Transactions of Imperial Moscow University on Mathematics and Physics, no. 10, pp. 1 - 93, 1893;

[2] D. L. Chapman, "VI.On the rate of explosion in gases," Phil. Mag. and Jour. Sci., vol. 47 (284), no. 5, 1899, pp. 90104

[3] E. Jouguet, “On the propagation of chemical reactions in gases," Journal de Mathématiques Pures et Appliquées, no. 7 , pp. 347-425, 1905 (in French);

[4] Y. B. Zeldovich, "On the theory of the propagation of detonation in gaseous systems," Journal of Experimental and Theoretical Physics, no. 10, pp. 542-568, 1940, November;

[5] J. V. Neumann, Theory of detonation waves, Aberdeen Proving Ground, Maryland: Office of Scientific Research and Development, 1942, Report No. 549, Ballistic Research Laboratory File No. X-122;

[6] W. Döring, “On the detonation process in gases,” Annalen der Physik, no. 43, pp. 421-436, 1943 (in French);

[7] A. S. Tityapkin and V. E. Volkov, "The pressure profile of stationary detonation wave as the basis of theoretical stability estimate for the detonation of condensed and gas systems," Automation of technological and businessprocesses (ATBP), vol. 3, pp. 9-16, 2010;

[8] Y. B. Zel'dovich and A. S. Kompaneyets, Theory of detonation. State Technical Press, 1955;

[9] M. V. Batalova et al., "Calculation of the structure of detonation waves," Journal of Applied Mechanics and Technical Physics, no. 3, pp. 73-80, 1971;

[10] M.A. Nettleton, Gaseous Detonations: their nature, effects and control. London: Chapman and Hall, 1987. 